\title{
The Processability Improvement of Duplex Stainless Steel
}

\author{
Shangtan Liu', Jann van Benthem ${ }^{2}$ \\ ${ }^{1}$ Material Sciences and Engineering Institute, Shanghai University, Shanghai, China \\ ${ }^{2}$ NIKOS, University of Twente, Enschede, The Netherlands \\ Email: liushangtan2@163.com, j.w.I.vanbenthem@utwente.nl
}

Received 30 March 2016; accepted 15 April 2016; published 18 April 2016

Copyright (C) 2016 by authors and OALib.

This work is licensed under the Creative Commons Attribution International License (CC BY). http://creativecommons.org/licenses/by/4.0/

(c) (i) Open Access

\section{Abstract}

This paper focuses on the duplex stainless steel processability and presents many practical technological approaches which are applied in many steel companies on how to improve the processability. First, take into consideration an appropriate hot working temperature; second, make sure cooling rate higher than $15^{\circ} \mathrm{C} / \mathrm{s}$; and third, conduct annealing treatment before delivery.

\section{Keywords}

\section{Stainless Stainless, Processability, $\sigma$ Precipitation}

\section{Subject Areas: Metal Material}

\section{Introduction}

Baosteel is a top list steel company around the world and can deliver many kinds of duplex stainless steel (DSS in short) products, including the steel grade of S32101, S32205, S31803, S32507 etc. Every year Baosteel produces duplex stainless steel tens of thousands tons. But duplex stainless steel is difficult to make. One challenge is inclusion defects in the billets; another is crack defect after hot working because of the precipitating of brittle phase. Figure 1 shows the inclusion defects on a plate. Figure 2 shows the cracks on a DSS plate. So in most of the steel companies, the yield rate of duplex stainless steel may be as low as $60 \%$ - 65\%, compared to as high as that of $80 \%$ - $85 \%$ for austenite stainless steel. For Baosteel it's also very important to understand why these defects occur and manage to decrease or even resolve these difficulties to improve the quality and increase the yield ratio to enhance Baosteel's competence ability in DSS.

The duplex stainless steel (brief in DSS) is a kind of good-performance stainless steel because of high strength, good corrosion resistance and low cost attributing by its low nickel content, with ferrite and austenite roughly accounting for about $50 \%$ to $50 \%$ respectively, the main elements including $0.01 \%-0.08 \%$ C, $18 \%-26 \%$ $\mathrm{Cr}, 3 \%-8 \% \mathrm{Ni}$, sometimes also having $\mathrm{Mo}, \mathrm{Cu}, \mathrm{W}, \mathrm{Nb}, \mathrm{N}$. If it is compared to ferrite steel, it has better 

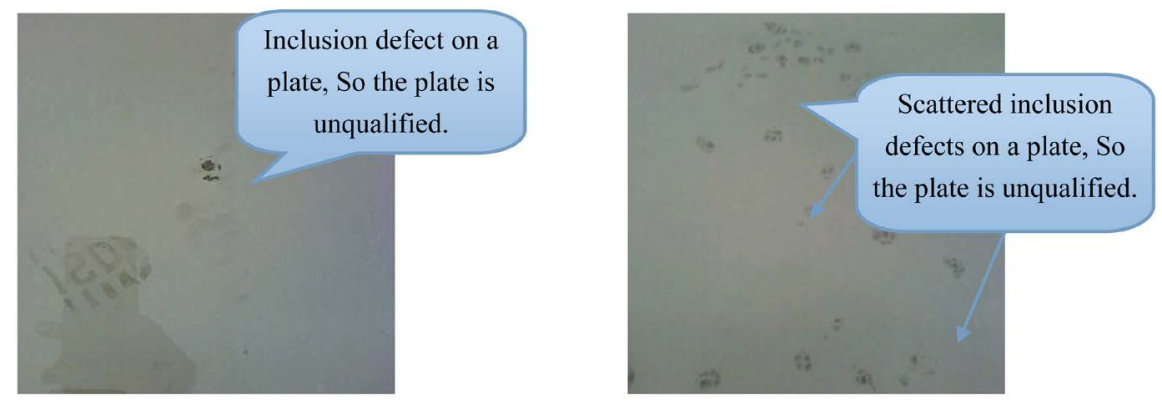

Figure 1. Inclusion defects on a plate for DSS $(\times 10)$.

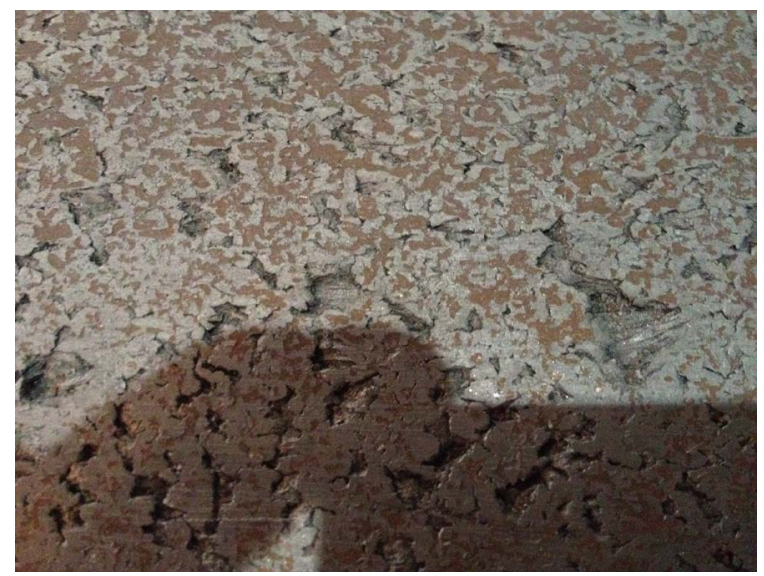

Figure 2. The cracks on a DSS plate $(\times 10)$.

plasticity, tenacity, better anti-intergranular corrosion capacity and easy to be welded, higher heat conductivity, no brittleness at ambient temperature. If it is compared to austenite steel, it has higher tensile strength, better chloride anti-stress corrosion and anti hole corrosion ability of which people evaluate it by corrosion equivalent $\mathrm{PRE}=\% \mathrm{Cr}+3.3(\% \mathrm{Mo})+1.65 \% \mathrm{~W}+16(\% \mathrm{~N})$. At the same time, it is also a nickel-saving ecofriendly stainless steel. DSS is applied widely in oil and gas industry, chemical industry, pulp and paper industry, water systems, desalination plants, pollution control equipments, chemical tankers for its better cost performance.

But because it constitutes high $\mathrm{Cr}$ and Mo, many brittle compounds like $\sigma, \chi$ and $R$ will precipitate from the high temperature of $900^{\circ} \mathrm{C}$ till the low temperature of $400^{\circ} \mathrm{C}$. So it's necessary to make sure cool rapidly through that temperature range.

\subsection{Duplex Stainless Steels and Market Applications}

Duplex grades production, worldwide, represent nowadays about 300,000 tonnes about $1 \%$ of the total Stainless Steel production. DSS products mainly are plates, tubes, bars, wires, coils. For those productions weight savings are often obtained taking advantage of their high mechanical properties. Most of the applications concerns highly corrosion resistance properties encountered in process industry. (Chemical, petrochemical, off-shore, chemical tankers, pulp and paper industry, pollution control equipments (Flue Gas Desulfurization), desalination, seawater applications, see Figures 3-5 from Google picture). In those applications DSS have always been very competitive compared to 317 and 904 grades due to their reduced Nickel content and high mechanical properties compared to austenitic which make it possible to reduce thicknesses.

Figures 3-5 are the main application for DSS [1].

\subsection{DSS Corrosion Resistance}

According to Michael Mcguire [2], DSS has much better corrosion resistance performance compared to other stainless steel. Usually pitting resistance ability for stainless steel is evaluated by PREN $=\% \mathrm{Cr}+3.3(\% \mathrm{Mo})+$ 

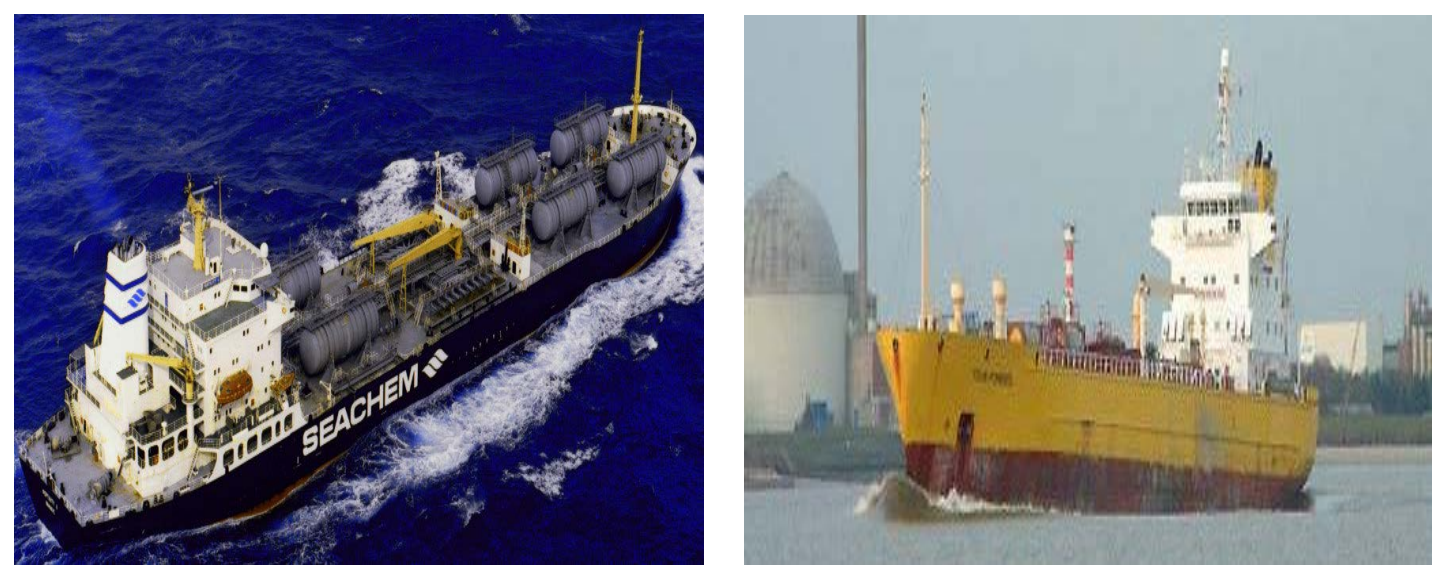

Figure 3. Chemical tanker.

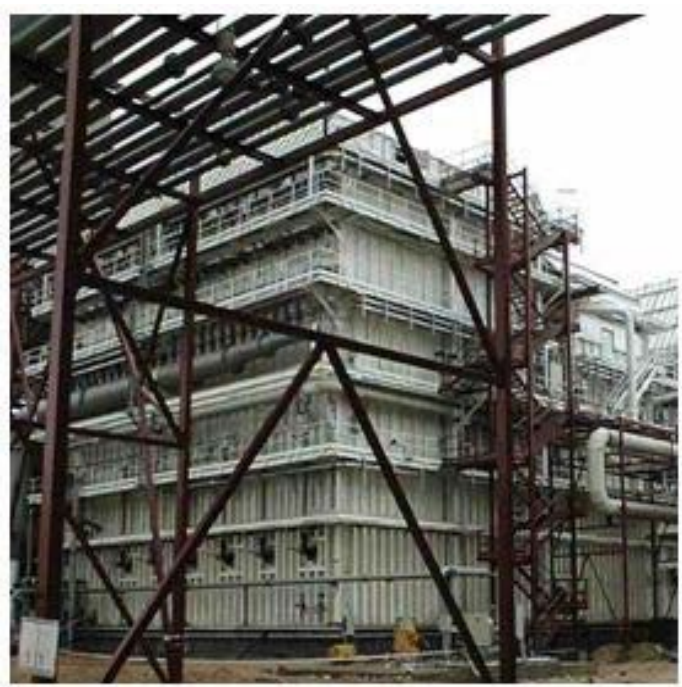

Figure 4. Pollution control equipments made from UR 52N, 2507Cu.

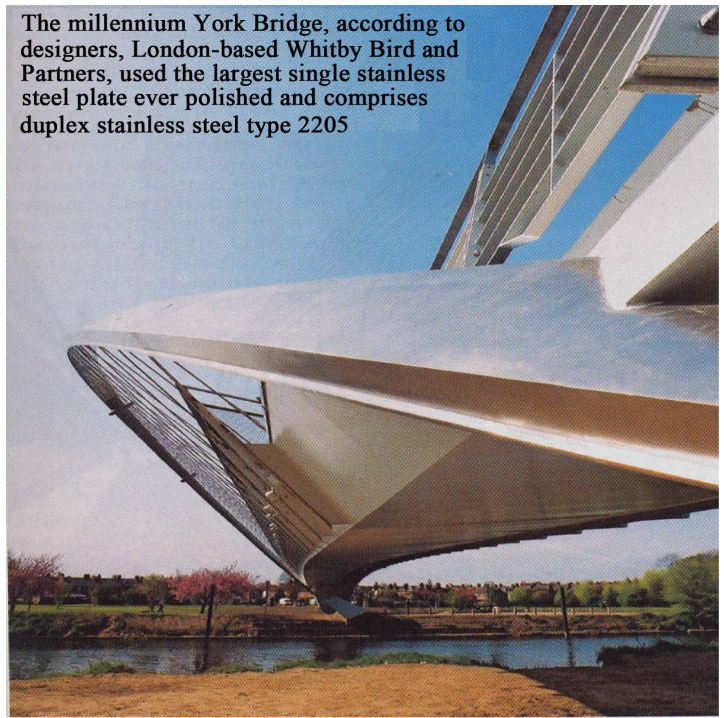

Figure 5. York millennium bridge made out of 2205 duplex plates. 
1.65(\%W) $+16(\% \mathrm{~N})$, PREN, short of Pitting Resistance Equivalent Number, a measurement of the corrosion resistance of stainless steel. that is why DSS has much better pitting resistance capability than other stainless steel. PREN value for stainless steel. See Table 1.

Figure 6 and Figure 7 [2] shows DSS grade such as S32750, S31803 have much higher critical pitting temperature and stress corrosion cracking temperature than S30403 and S31603 in chlorine containing solution.

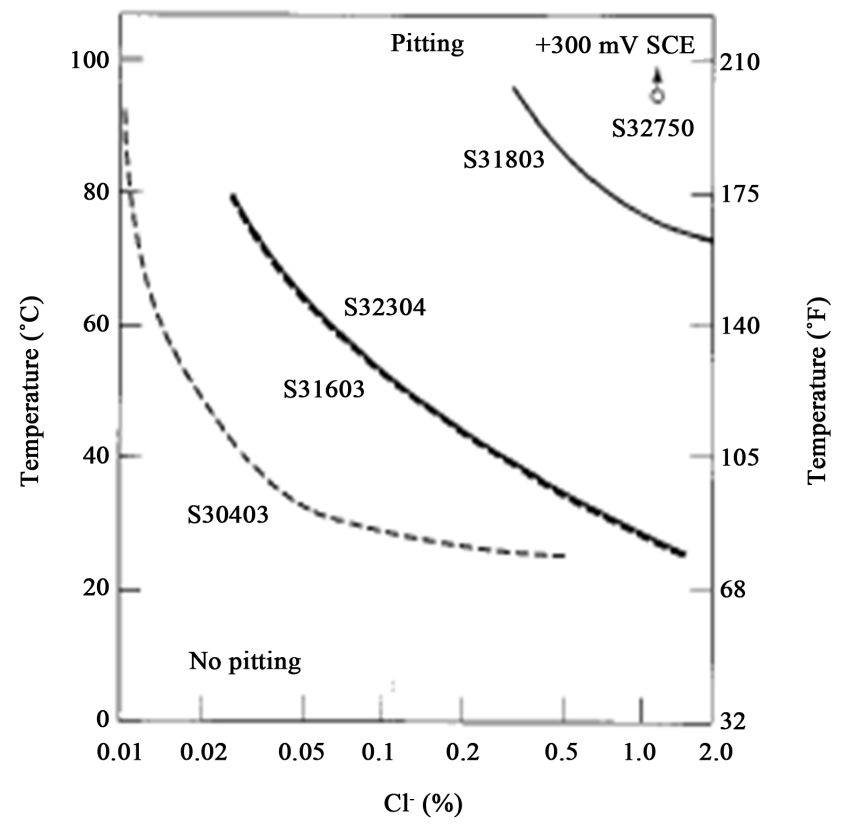

Figure 6. Critical Pitting Temperature (CPT) comparison within stainless steel.

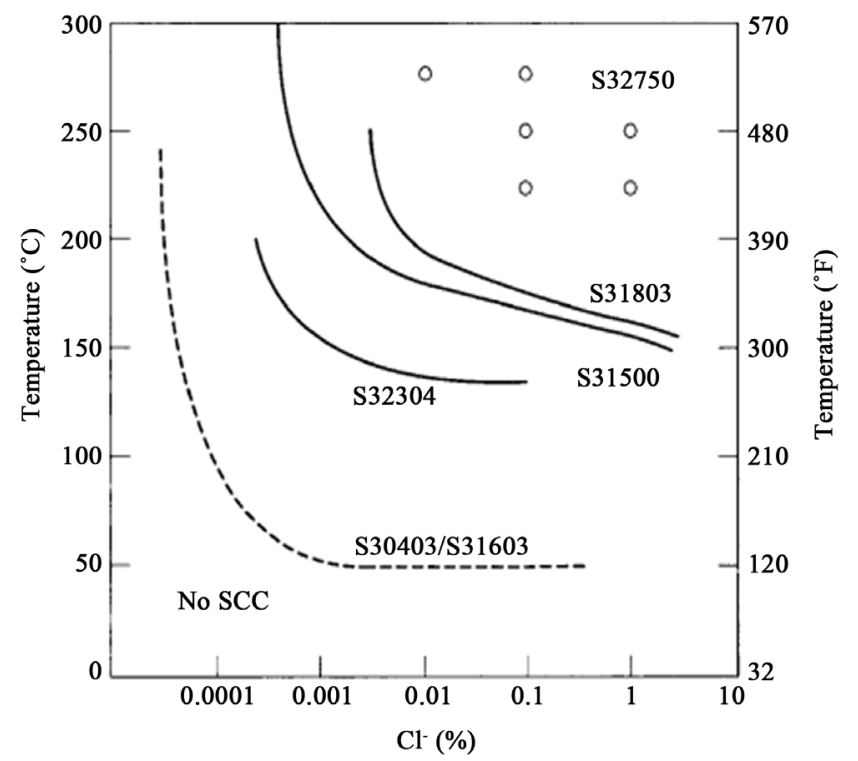

Figure 7. Stress Corrosion Cracking Temperature (SCCT) comparison within stainless steel.

Table 1. PREN value for stainless steel.

\begin{tabular}{ccccccccccc}
\hline Alloy & 430 & 439 & 201 & 304 & 316 & 2101 & 2103 & 2205 & 2507 \\
\hline PREN & 15 & 17 & 17 & 19 & 24 & 26 & 28 & 35 & 38 &
\end{tabular}




\section{Expected Researching Purpose}

How to eliminate, decrease or alleviate those defects occurring in duplex stainless steel processes and make DSS more processable and less defects, is a worthy topic for insiders to put more efforts to think if some technological approach can be found to improve its quality and enhance its yield rate to say $10 \%$ higher to maybe $70 \%-75 \%$.

\section{Characteristics of $\alpha$ and $\gamma$ Phase in DSS}

The duplex stainless steel constitutes mainly of $\mathrm{C}$, Si, Mn, Cr, Ni, Mo, Cu, N, V, Ti etc. $\alpha$ phase is BCC (bodycentered cubic) structure and $\gamma$ is FCC (face-centered cubic).

$\alpha$ is relatively soft and easily to be deformed and in contrast $\gamma$ is harder and difficult to be deformed, so the deformation begins from $\alpha$ and later to $\gamma$. Cracks will occur when the deformation can't smoothly transmit from $\alpha$ to $\gamma$. But many factors have significant influence on deformation process.

\subsection{Element Contents}

First, element contents exert obvious impact on duplex stainless steel's deformation ability. Generally, the contents of $\mathrm{Si}, \mathrm{Mo}, \mathrm{Cr}, \mathrm{V}$, Ti increase the $\alpha$ phase amount and that of $\mathrm{C}, \mathrm{N}, \mathrm{Ni}, \mathrm{Cu}, \mathrm{Mn}$ contribute more to $\gamma$ phase amount. It is reported that whenever the $\gamma$ percentage is more than $20 \%$ and less than $80 \%$, cracks is more likely to occur (see Figure 8).

\subsection{Schaeffler Microstructure Chart}

According to schaeffler's test, the element contents have direct influence on duplex stainless steel's microstructure, determining the percentages of $\mathrm{A}(\gamma), \mathrm{F}(\alpha)$ and $\mathrm{M}$ (martensite). See Figure 9.

But S32304, S32205 and S32507 both have the roughly 50\% $\alpha$ and 50\% $\gamma$, so they have the worse deformation ability in stainless steel. It's a big challenge to make them easy to process.

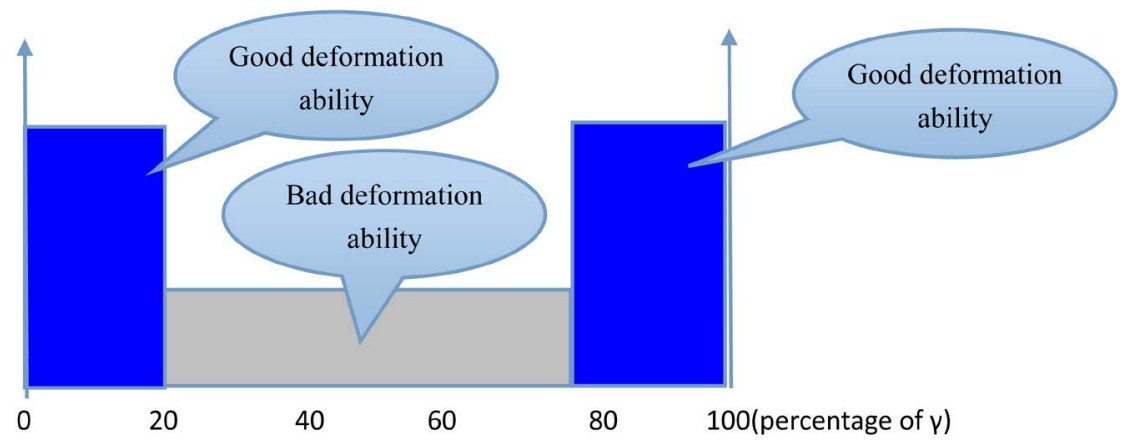

Figure 8. The deformation ability vs. percentage of $\gamma$.

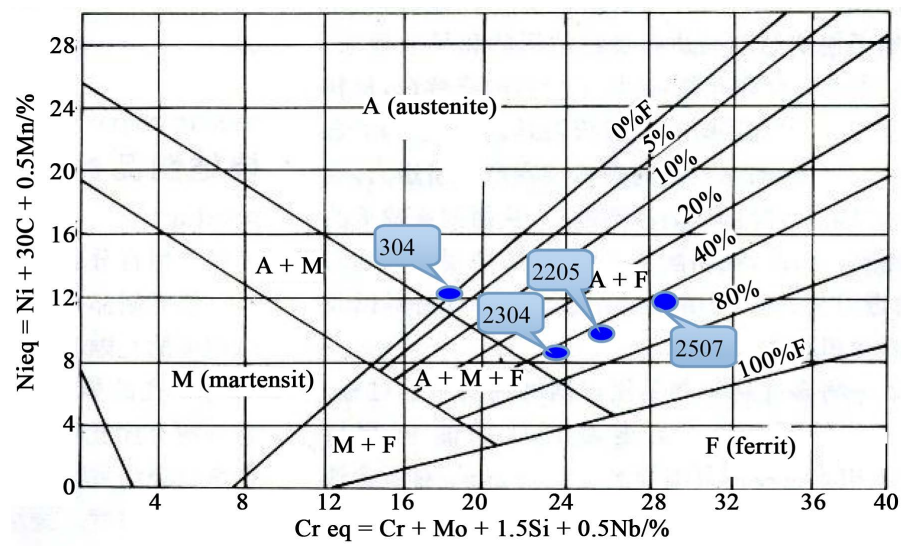

Figure 9. The element contents determine the percentages of $\mathrm{A}(\gamma), \mathrm{F}(\alpha)$ and $\mathrm{M}$ (martensite). 


\section{The Most Important Technical Parameters on DSS Formation}

\subsection{Hot Working Temperature Consideration}

If temperature exceeds $1300^{\circ} \mathrm{C}$, only one phase of $\alpha$ is maintained, theoretically it's good for deformation, but its negative aspect is the grain size of $\alpha$ will grow up rapidly and oppositely it make the thermoplasticity of duplex stainless steel drop dramatically and present fragile behaviour. So it's harmful to increase the temperature too high. On the other hand, if the temperature do not climb to $1000^{\circ} \mathrm{C}$, so many types of brittle phases such as $\sigma, \chi$, $\mathrm{R}$ will appear with worst plasticity to make it difficult to deform. As a result it's appropriate to choose a temperature between $1050^{\circ} \mathrm{C}$ and $1200^{\circ} \mathrm{C}$ when being hot worked.

Chi-Shang Huang, Chia-Chang Shih [3] 2005 found that $\sigma$ phase precipitates at about $600^{\circ} \mathrm{C}-1000^{\circ} \mathrm{C}$, of which it is a phase rich in chromium and molybdenum. And it not only will cause substantial damage to ductility and toughness of steel material, but it will also undermine corrosion resistance of DSS. Figure 10(a) and Figure 10(b) are the photograph taken by Optical Microscope and Scanning Electron Microscope.

\subsection{N content, $\sigma$ Phase Control, Cooling Rate Consideration}

$\sigma$ phase is harmful to DSS because it is fragile and vulnerable to corrode. But $\mathrm{N}$ can decrease the $\sigma$ phase amount effectively, see Figure 11. It can be found that the more the nitrogen content is, the less is the $\sigma$ phase content. This is because nitrogen is an austenitic stabilizing element. It will directly increase the austenitic phase content and decrease the percentage of ferritic phase in DSS, thereby indirectly leaving less room for $\sigma$ phase

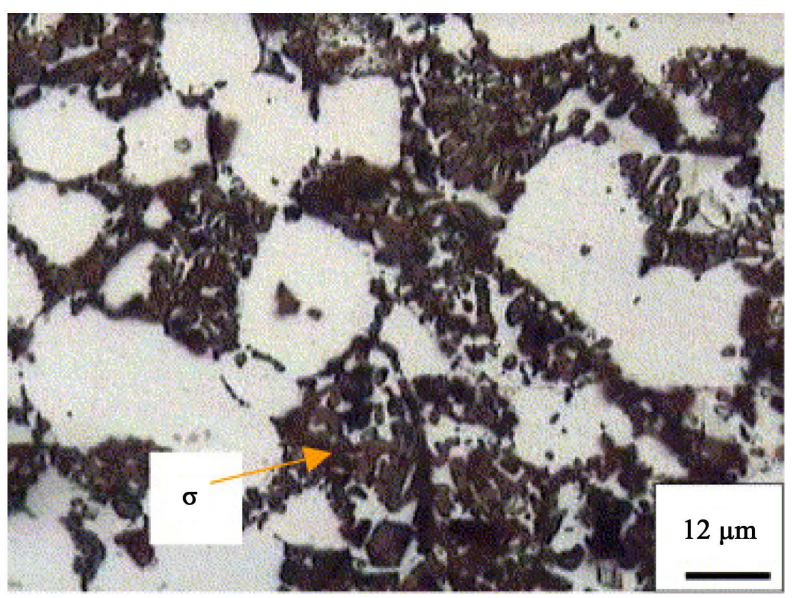

(a)

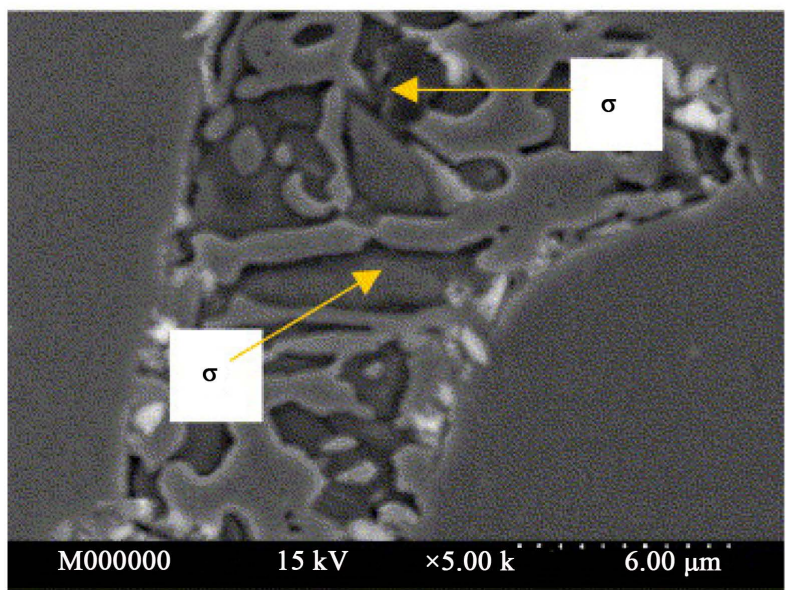

(b)

Figure 10. $\sigma$ phase taken by Optical Microscope and Scanning Electron Microscope. 


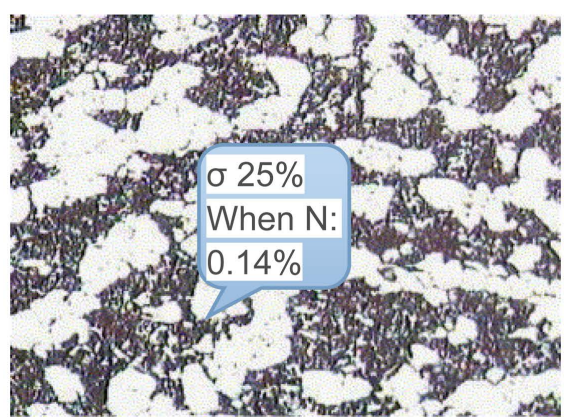

(a)

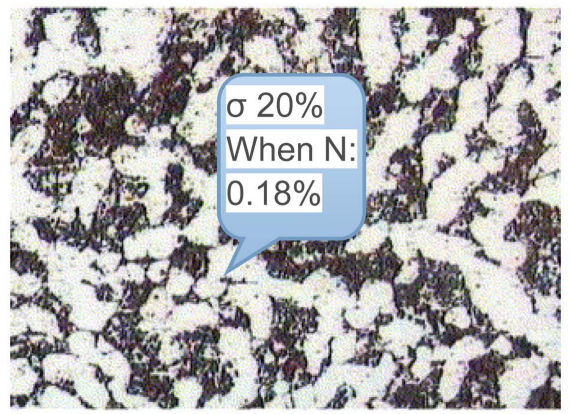

(b)

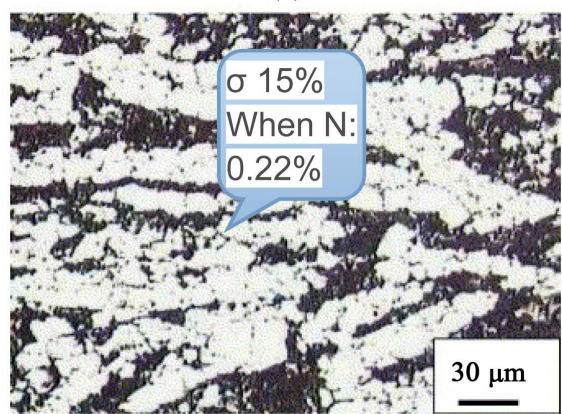

(c)

Figure 11. The higher the $\mathrm{N}$ content the less the $\sigma$ phase $(\times 500)$.

after precipitation to develop. Consequently, the addition of nitrogen content does help slow down the precipitation rate of $\sigma$ phase.

Henrik Sieurin, Rolf Sandström 2005 [4] found that the volume fraction of $\sigma$ phase is related to temperature and time, see Figure 12. The precipitation starts at around $920^{\circ} \mathrm{C}$. The maximum of $\sigma$ phase precipitation is found around $850^{\circ} \mathrm{C}$. No sigma phase appears below $650^{\circ} \mathrm{C}$. The longer stayed at $850^{\circ} \mathrm{C}$, the more of the $\sigma$ phase precipitation [5] [6].

T.H. Chen, J.R. Yang 2001 [7] and L.H. Chiu, W.C. Hsieh, C.H. Wu 2003 [8] found that the $\sigma$ phase amount precipitated change dramatically with the cooling rate. In order to avoid $\sigma$ phase precipitation, the cooling rate should approximately be in the range more than $0.25 \mathrm{~K} \cdot \mathrm{S}^{-1}$. See Figure 13 and Figure 14.

\subsection{Intermetallic Phase Percentage Volume in DSS}

J.-O. NILSSON, P. KANGAS, T. KARLSSON, and A. WILSON [9] got the Volume percentage of intermetallic phase through the approach of ISO 9042, found the precipitation of intermetallic phase has significant influence on impact toughness, as well as observed the Cr2N and $\sigma$ articles through backscattered image by EPMA and distribution of element N, Cr, Mo through X-ray when DSS aged at $900^{\circ} \mathrm{C} / 72 \mathrm{~h}$. See Table 2, Figure 15 and Figure 16 [10].

They [9] also observed the backscatter electron micrograph by SEM when DSS aged for $72 \mathrm{~h}$ at various temperatures. Bright one is $\sigma$ article and dark is $\mathrm{Cr}_{2} \mathrm{~N}$. See Figure 17. 


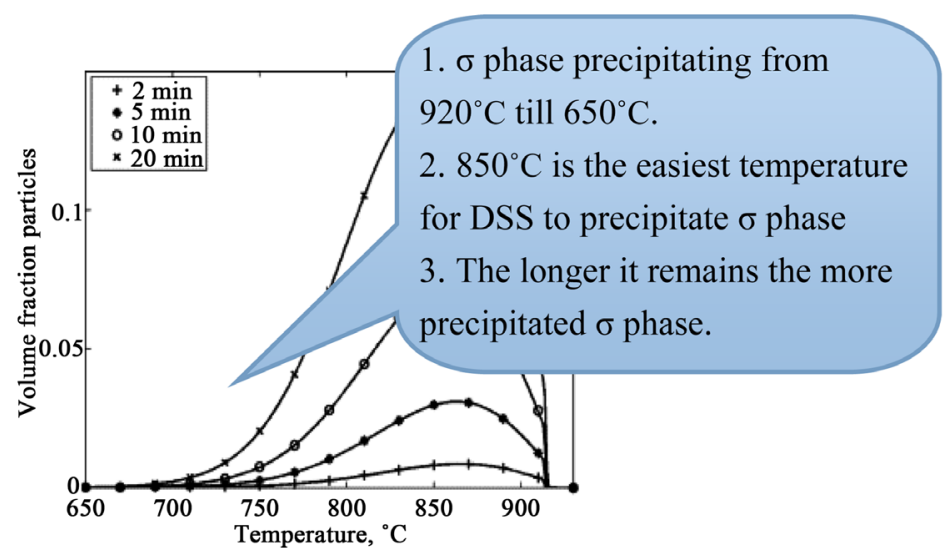

Figure 12. The volume fraction of $\sigma$ phase as a function of temperature and time.

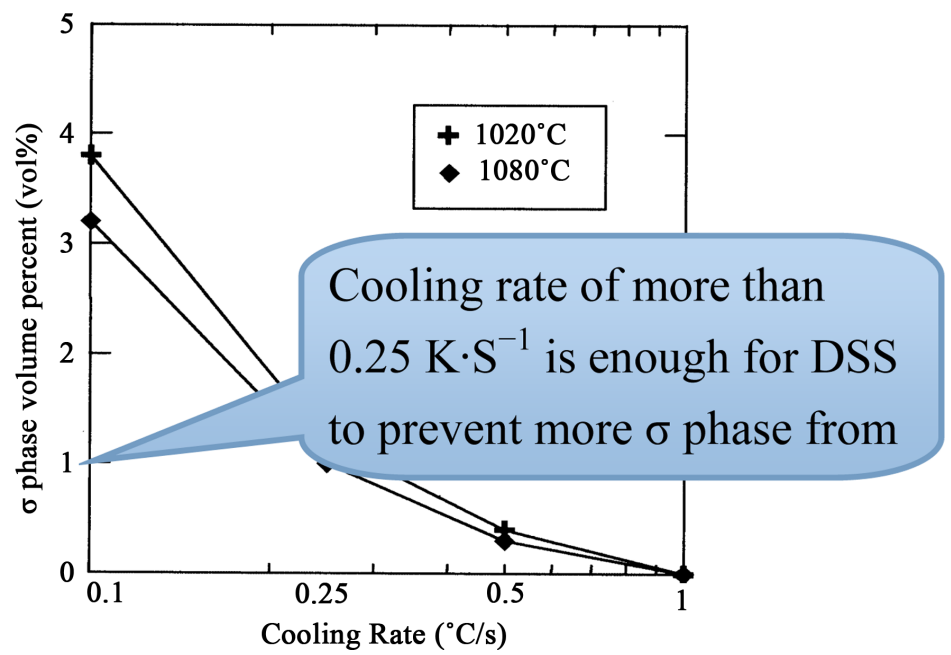

Figure 13. Volume of phase changes with cooling rates.

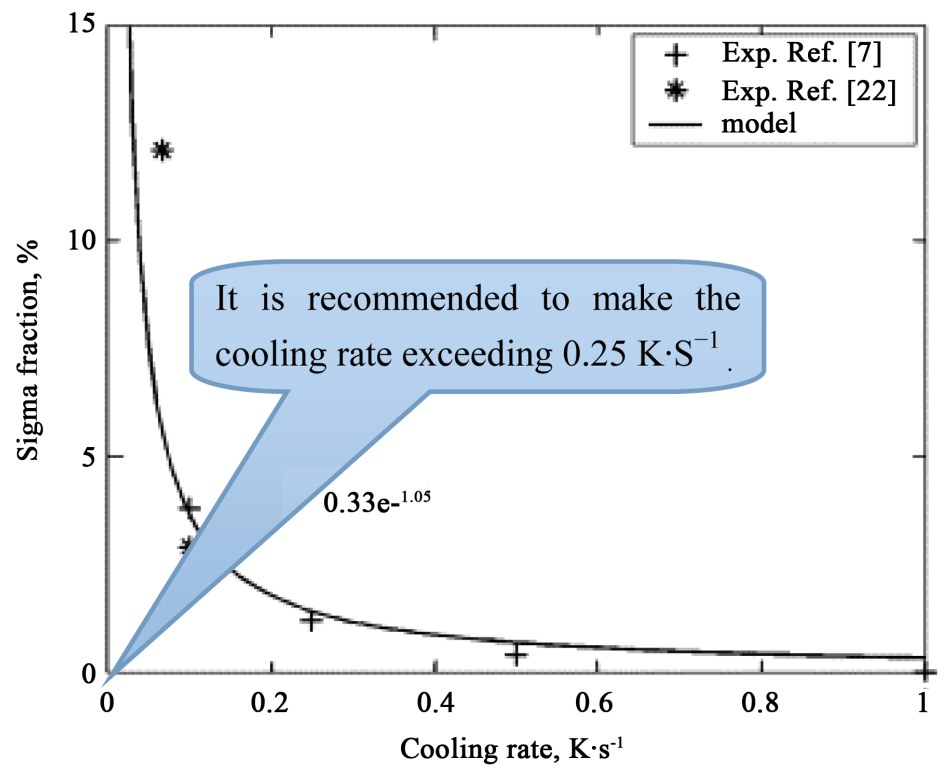

Figure 14. $\sigma$ phase at room temperature as a function of cooling rate. 


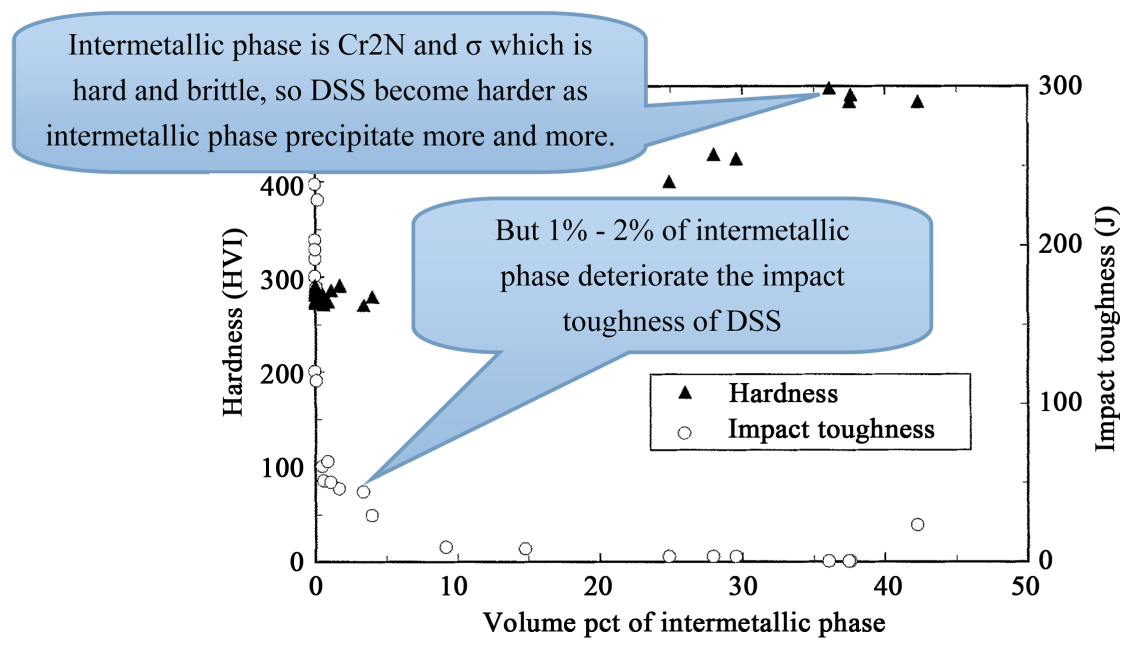

Figure 15. The volume of intermetallic phase has obvious influence on impact toughness.

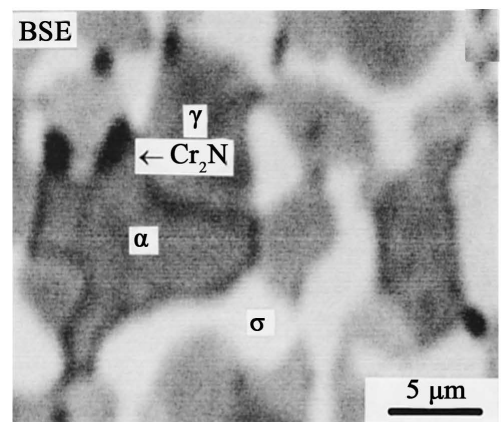

(a)

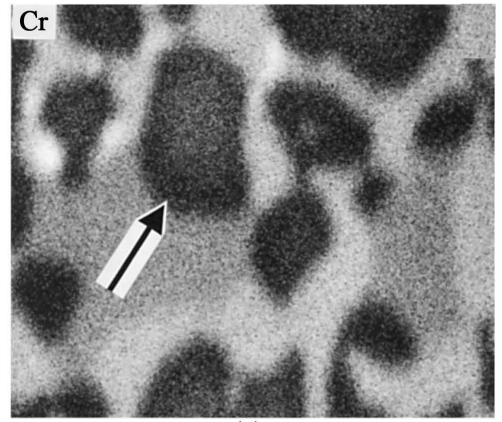

(c)

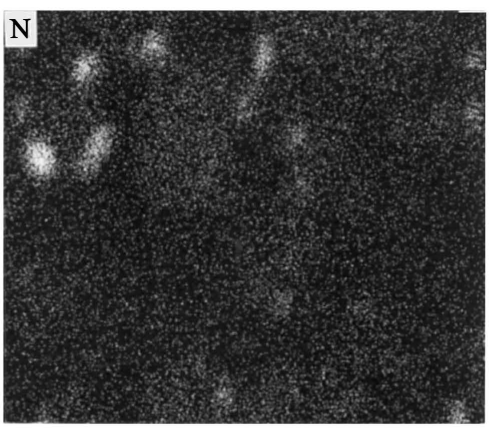

(b)

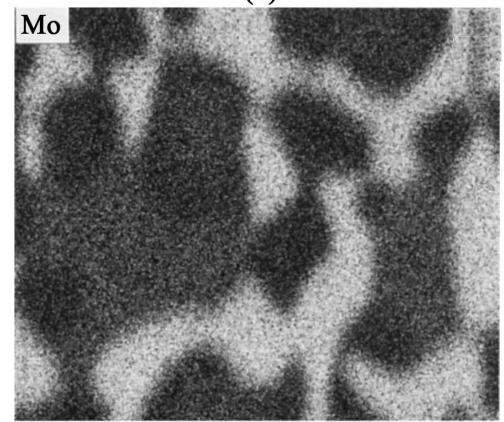

(d)

Figure 16. (a) $\mathrm{Cr}_{2} \mathrm{~N}$ and $\sigma$ articles and element distribution of (b) $\mathrm{N}$; (c) $\mathrm{Cr}$ and (d) Mo.

Table 2. Volume percentage of intermetallic phase.

\begin{tabular}{cccccccc}
\hline Temperature, ${ }^{\circ} \mathrm{C} /$ time & $1 \mathrm{~min}$ & $3 \mathrm{~min}$ & $9 \mathrm{~min}$ & $27 \mathrm{~min}$ & $81 \mathrm{~min}$ & $72 \mathrm{~h}$ & T-C, equilibrium \\
\hline 975 & 0 & 0 & 0 & 0 & 0 & $0.6 \pm 0.3$ & 0 \\
950 & 0 & 0 & 0 & 0 & 0 & $15.6 \pm 1.6$ & 0 \\
900 & $0.1 \pm 0.1$ & $0.1 \pm 0.1$ & $0.9 \pm 0.5$ & $4.0 \pm 0.9$ & $14.2 \pm 1.7$ & $32.5 \pm 1.8$ & 0 \\
850 & 0 & $0.2 \pm 0.2$ & $3.4 \pm 0.9$ & $14.8 \pm 1.4$ & $24.9 \pm 1.7$ & $36.1 \pm 2.0$ & 0 \\
800 & 0 & $0.2 \pm 0.2$ & $1.1 \pm 0.4$ & $9.2 \pm 1.4$ & $28.0 \pm 1.8$ & $37.5 \pm 2.0$ & 10.6 \\
750 & 0 & 0 & 0 & $1.7 \pm 0.6$ & $29.6 \pm 1.9$ & $37.6 \pm 1.9$ & 24.5 \\
700 & 0 & 0 & 0 & 0 & $0.5 \pm 0.3$ & $42.3 \pm 2.4$ & 31.1 \\
\hline
\end{tabular}




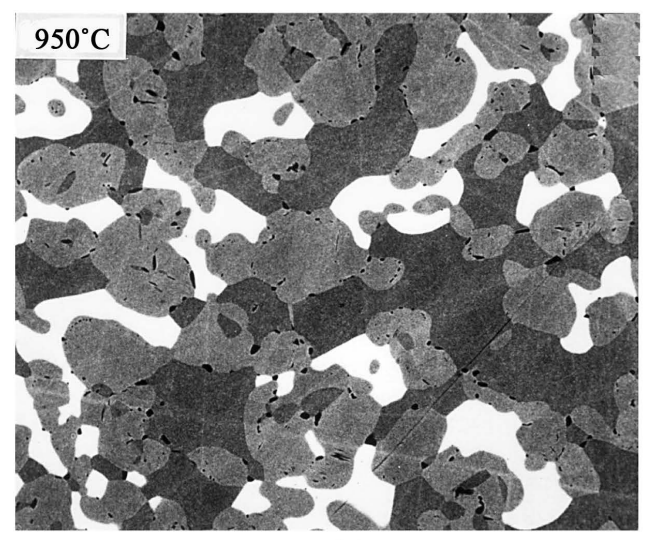

(a)

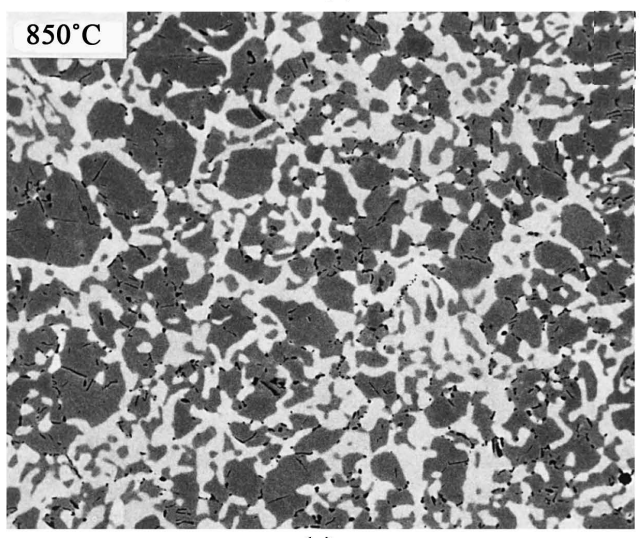

(c)

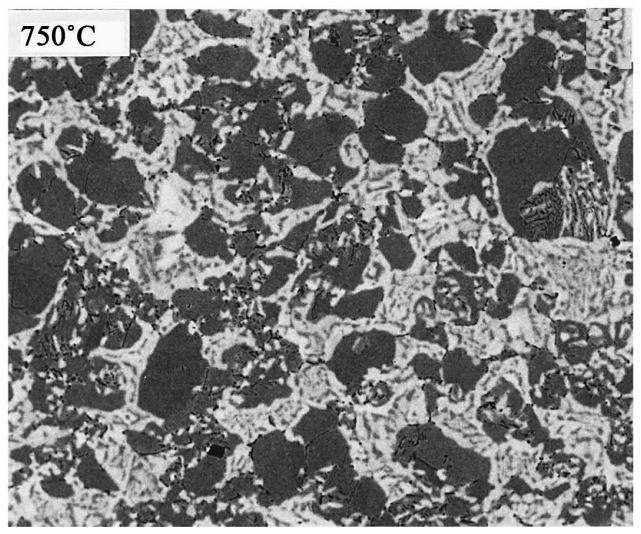

(e)

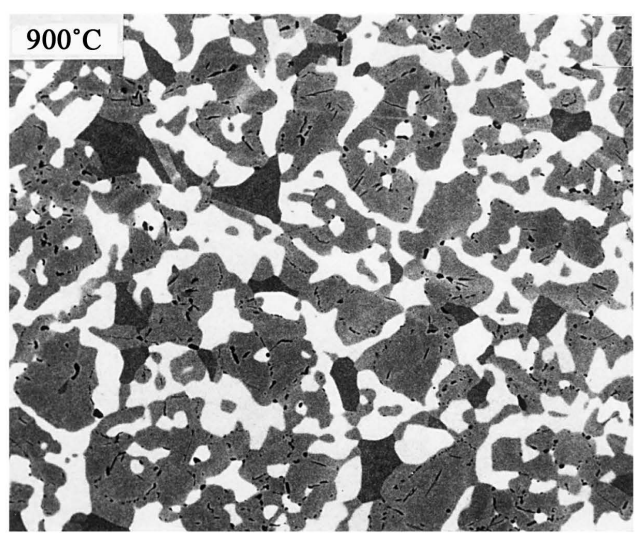

(b)

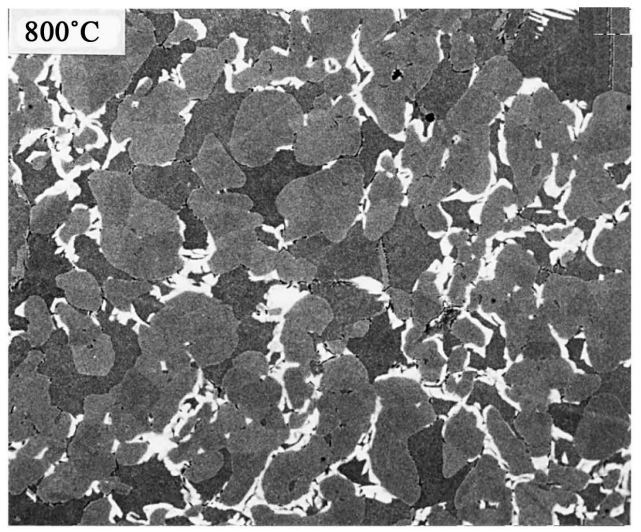

(d)

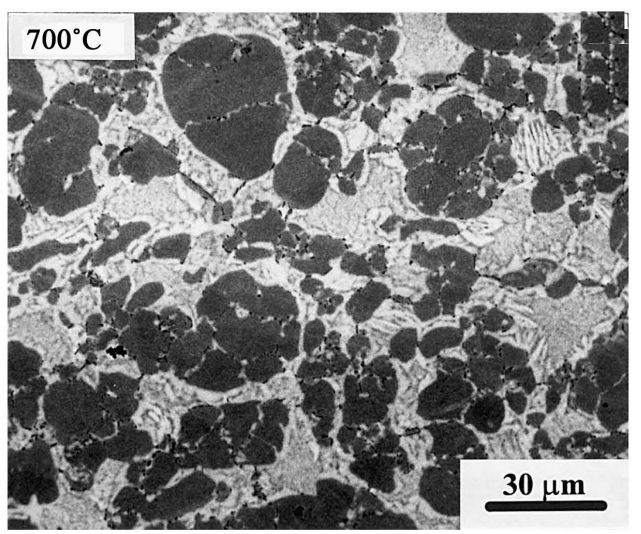

(f)

Figure 17. $\sigma$ article (bright) and $\mathrm{Cr}_{2} \mathrm{~N}$ article (dark) by SEM.

The phase diagram was calculated through Thermo-Calc [9] shows the stability areas of liquid, austenite, ferrite, $\mathrm{Cr}_{2} \mathrm{~N}, \sigma$ phase, and $\mathrm{M}_{23} \mathrm{C}_{6}$. See Figure 18.

Also the phase fractions of liquid, austenite, ferrite, $\mathrm{Cr}_{2} \mathrm{~N}, \sigma$ phase, and $\mathrm{M}_{23} \mathrm{C}_{6}$ [9] is calculated by ThermoCalc. See Figure 19.

\subsection{Recommended Hot Rolling and Annealing Temperature for DSS}

According to Michael Mcguire [2], DSS should implement annealing process before the end usages to achieve the equilibrium composition within both the ferrite and austenite and rebalance the volume fraction of the ferrite and austenite as well as dissolve the unwanted intermetallic phase. See Table 3. 


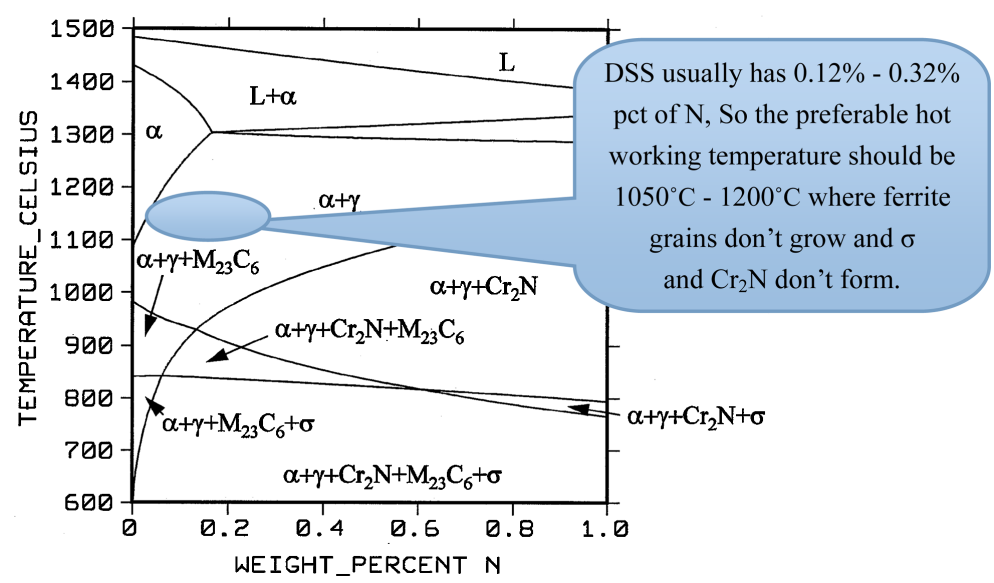

Figure 18. The phase diagram of DSS calculated through Thermo-Calc.

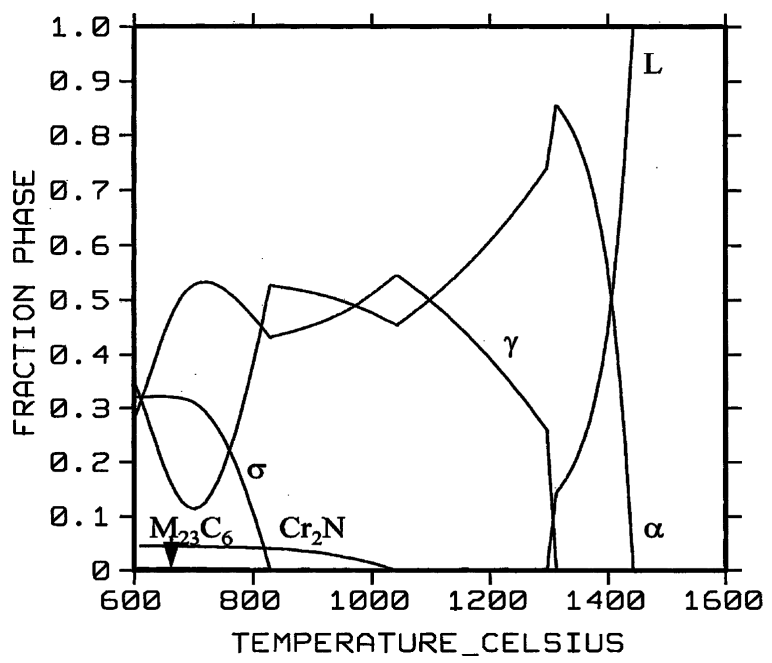

Figure 19. The phase fractions of liquid, austenite, ferrite, $\mathrm{Cr}_{2} \mathrm{~N}, \sigma$ phase, and $\mathrm{M}_{23} \mathrm{C}_{6}$ for DSS.

Table 3. Recommended annealing temperature for DSS.

\begin{tabular}{ccc}
\hline Alloy & Annealing temperature, ${ }^{\circ} \mathrm{C}$ & Annealing temperature, ${ }^{\circ} \mathrm{F}$ \\
\hline Lean Duplex, $\mathrm{Cr}+\mathrm{Mo} \leq 23$ & $1010-1100$ & $1850-2010$ \\
Medium Grade Duplex, $23<\mathrm{Cr}+\mathrm{Mo} \leq 26$ & $1040-1100$ & $1900-2010$ \\
High grade Duplex, $26<\mathrm{Cr}+\mathrm{Mo}$ & $1050-1150$ & $1925-2100$ \\
\hline
\end{tabular}

\subsection{Welding of DSS Technology}

It's important to consider the welding parameters such as Filler, heat input, shielding gas, preheat or not, max interpass, etc. See Table 4 for recommendation [11].

\section{Conclusions}

It's recommended to make DSS retain at the temperature between $1050^{\circ} \mathrm{C}$ to $1200^{\circ} \mathrm{C}$, which can restrain the $\alpha$ grow and intermetallic phase precipitate to make DSS have a good deformation ability.

Nitrogen plays an important role for DSS's deformation ability and its higher pitting corrosion resistant and chlorine stress corrosion ability as well as higher strength. So adding more N to the DSS is doubtless an economical and effective way to gain better performances. 
Table 4. Recommended welding parameters for DSS.

\begin{tabular}{ccccc}
\hline Alloy & Filler & Heat input, $\mathrm{KJ} / \mathrm{cm}(\mathrm{max})$ & Shielding gas & Interpass, max \\
\hline $2003,2101,2304$ & 2209 & $5-25$ & Argon $+3 \% \mathrm{~N}_{2}$ & $150^{\circ} \mathrm{C}$ \\
2205 & 2209 & $5-25$ & Argon $+3 \% \mathrm{~N}_{2}$ & $150^{\circ} \mathrm{C}$ \\
2507 & $25 \mathrm{Cr}-10 \mathrm{Ni}-4 \mathrm{Mo}-\mathrm{N}$ & $5-25$ & Argon $+3 \% \mathrm{~N}_{2}$ & $150^{\circ} \mathrm{C}$ \\
\hline
\end{tabular}

It is imperative for DSS to be annealed at the temperature of $1050^{\circ} \mathrm{C}-1100^{\circ} \mathrm{C}$ before end usage. Because it can obtain the equilibrium composition within both the ferrite and austenite, rebalance the volume fraction of the ferrite and austenite as well as dissolve the unwanted intermetallic phase.

Always make sure to cool DSS whenever it experiences a hot working process as rapidly as you can. Only at a more than $0.25^{\circ} \mathrm{C}$ per second can it retain and avoid the brittle phase like $\alpha$ to precipitate. It means the min cooling rate of $15^{\circ} \mathrm{C} / \mathrm{s}$ or $900^{\circ} \mathrm{C} / \mathrm{min}$.

Many aspects should be taken into account for DSS when welding. First, filler of 2209 is suitable for 2101, 2304 and 2205; filler of 25Cr-10Ni-4Mo-N is suitable for 2507. Second, it's a key point to make sure controlling heat input at a $5-25 \mathrm{KJ} / \mathrm{cm}$ level, applying Argon $+3 \% \mathrm{~N}_{2}$ as yielding gas, with inter pass temperature on higher than $150^{\circ} \mathrm{C}$.

\section{References}

[1] Charles, J. (2008) Duplex Stainless Steels, a Review after DSS’07 in Grado. Revue de Métallurgie Paris, 105, 155171. http://dx.doi.org/10.1051/metal:2008028

[2] McGuire, M. (2008) Stainless Steels for Design Engineers.

[3] Huang, C.-S. and Shih, C.-C. (2005) Effects of Nitrogen and High Temperature Aging on $\sigma$ Phase Precipitation of Duplex Stainless Steel. Materials Science and Engineering: A, 402, 66-75. http://dx.doi.org/10.1016/j.msea.2005.03.111

[4] Sieurin, H. and Sandström, R. (2006) Sigma Phase Precipitation in Duplex Stainless Steel 2205. Materials Science and Engineering: A, 444, 271-276. http://dx.doi.org/10.1016/j.msea.2006.08.107

[5] Daniella Caluscio, D.S. (2016) Kinetic Study to Predict Sigma Phase Formation in Duplex Stainless Steels. Metallurgical and Materials Transactions A, 47, 1554-1565. http://dx.doi.org/10.1007/s11661-016-3323-z

[6] Warren, A.D., Guo, Z., Younes, C.M., et al. (2015) Quantification of Sigma-Phase Evolution in Thermally Aged 2205 Duplex Stainless Steel. Journal of Materials Science, 51, 694-707. http://dx.doi.org/10.1007/s10853-015-9131-9

[7] Chen, T.H. and Yang, J.R. (2001) Effects of Solution Treatment and Continuous Cooling on $\sigma$-Phase Precipitation in a 2205 Duplex Stainless Steel. Materials Science and Engineering: A, 311, 28-41. http://dx.doi.org/10.1016/S0921-5093(01)00911-X

[8] Chiu, L.H., Hsieh, W.C. and Wu, C.H. (2003) Cooling Rate Effect on Vacuum Brazed Joint Properties for 2205 Duplex Stainless Steels. Materials Science and Engineering: A, 354, 82-91. http://dx.doi.org/10.1016/S0921-5093(02)00911-5

[9] Nilsson, J.-O., Kangas, P., Karlsson, T. and Wilson, A. (2000) Mechanical Properties, Microstructural Stability and Kinetics of s-Phase Formation in 29Cr-6Ni-2Mo-0.38N Superduplex Stainless Steel. Metallurgical and Materials Transactions A, 31, 35-45. http://dx.doi.org/10.1007/s11661-000-0050-1

[10] Liu, X.Y., Xia, K.D., Niu, J.C., Xiang, Z., Yan, B. and Lu, W. (2015) Effects of Heat Treatment on Microstructure and Pitting Corrosion Resistance of 2205 Duplex Stainless Steel. International Journal of Electrochemical Science, 10, 9359-9369.

[11] Alvarez-Armas, I. (2008) Duplex Stainless Steels: Brief History and Some Recent Alloys. Recent Patents on Mechanical Engineering, 1, 51-57. http://dx.doi.org/10.2174/2212797610801010051 